Article

\title{
Setting the Methodological Framework for Accessibility in Geo-Mining Heritage Settings-An Ongoing Study of Iglesiente Area (Sardinia, Italy)
}

\author{
Nađa Beretić * (D) and Alessandro Plaisant $D$ \\ Department of Architecture, Design and Urbanism, University of Sassari, 07041 Alghero, SS, Italy \\ * Correspondence: nberetic@uniss.it; Tel.: +39-3664571049
}

Received: 31 March 2019; Accepted: 25 June 2019; Published: 28 June 2019

\begin{abstract}
This paper aims to discover why and how accessibility is fundamental to sustainable local development in heritage settings. We discussed the dimensions and variables of accessibility that control the development. Correspondingly, we proposed an interpretative framework for sustainable development planning and management of low urbanized spatial settings and accessibility for the Iglesiente Geo-mining heritage in Sardinia (Italy). The Iglesiente area is affected by a deep post-mining crisis that is reflected in poor socioeconomic conditions and an evident space oriented set of problems (a disorder in landscape matrix, low readability of space, scarce infrastructure and low accessibility). To revert negative trends of space-related problems, the paper proposes a theoretical model acting as an anticipatory landscape planning tool. The model copes with the context-specific problems in combination with theoretical findings. It acts at various scales through the definition of boundaries and variables of the internal and external environment, providing the territorial matrix of equity and cohesion. Furthermore, we argued the limitation and advantages of the model to its implementation capacity for the Geo-mining heritage and low-urbanized spatial settings. The empirical findings from an ongoing project about accessibility to territorial knowledge and services in the Iglesiente area, currently in progress, allow us to test and adjust the methodological framework in the next steps.
\end{abstract}

Keywords: accessibility; active mobility; heritage; low-density; Geo-mining Park; Sardinia; landscape knowledge; local development; Environmental Model; tourism

\section{Introduction}

After World War Two, the economic crisis hit the significant period of large-scale mining industrialization. A similar situation was notable around the whole of Europe. Rapid changes shaped by "substantial political trade-offs and long-term phasing-out scenarios" [1] were leading the mine closure. Rarely have the resources been exhausted but technical and market conditions have changed. Sardinia shared the destiny of mining conditions in Europe, entering the crisis in the mineral extraction sector, which gradually led to the closure of mines. The declining interest of private investors was followed by low adaptive capacity in the Sardinian mining sector. Private enterprises rapidly abandoned the mining sector from the 1960s and most mines in Sardinia were closed during the 1970s as "Mining territories had finished their productive phase and needed to reinvent themselves." [2]. Unfortunately, territories have never reinvented themselves because for centuries the mining industry has been the prevalent economic branch of these territories. Mineral extraction in Sardinia has a long history (about eight thousand years) [3]. The decline of the mining economy left the territories undeveloped, deepening the further socio-economic crisis as the consequences of single-function land-use. Correspondingly, the mining economy shaped Geo-morphological process, too. The relief process associates with almost all kinds of human activity, living habitats and behaviours: 
Transportation, Construction, Housing, Agriculture, Livestock, Socialization, Cults, Traditions and Customs. On the other hand, this complex condition of Sardinian ex-mining territory represents the uniqueness of mining activity and culture. In 1997, The United Nations Education, Scientific and Cultural Organization-“UNESCO” recognized Geo-mining Park in Sardinia (Italy) and its universal value of combined geological, mining, historical and environmental heritage [4]. Geo-mining Park in Sardinia is a pioneer of the heritage type. For the first time, "UNESCO" recognized the Geo-mining Park as an entire mining region instead of previous practice that aimed the protection of a single object. However, international recognition of universal values, administrative and legislative opportunities, did not help territorial prosperity. The Geo-mining Park remained fictive, excitant only in name. A few restoration projects were implemented punctually, lacking the integral planning, participative process and even heritage valorisation [5]. The post-mining phenomenon of the deep crisis still depicts the complete territory of Sardinian Geo-mining Park. Two categories affecting the crisis of ex-mining regions are prevalently people related issues (increasing depopulation and lack of economic prospective) and predominantly space oriented issues (a disorder in landscape matrix that causes low readability of heritage values, scarce infrastructure and low accessibility) [6]. This paper addresses space-oriented issues in the case of Iglesiente area that appertains to the Geo-mining Park in Sardinia.

Heritage is a vague, extensive and new term (arises after the 1970s) and there are "many definitions of the heritage concept as there are heritage practitioners" [7]. The evolving heritage concept is sensible to change, and it is actually changing. The evolution and expansion of the concept in both scope and direction paired with the new environment and sustainable development issues. The idea of sustainability opened up the path to the time-space continuum of heritage while opposing previous preservation character. The conceptual dynamism of heritage is natural, as people produce it according to their contemporary concerns and experiences [7]. However, the integration of cultural heritage in the planning process begins by the end of the twentieth century [8]. Focusing on relations between sustainable development and strategic spatial planning 'Heritage Urbanism' appears in the last few years [9]. It considers heritage as a valuable systems approach that acts as a regenerative layer and a common good for the development of the contemporary city [10]. Hence, there is much literature on individual heritage-related topic and project models but revitalization and enhancement of heritage integral within the historical and cultural context clearly lacks [11]. Adequate to the distinct identity of heritage and its local context, a renewal model has to be selected from a large number of models (both, basic, universal models of urban development and thematic) [11]. In this paper, we combined links and determinants of physical accessibility, suitable for the theme of Geo-mining heritage.

Antrop (2005) argues that "Accessibility" is one of the four major causes of landscape change, together with "Urbanization," "Globalization" and "Natural Calamities." Accessibility influences urban development and functional specialization of a place (e.g., market place or harbour); the growth of a place and the development of its economic or political power [12]. An increasing number of studies recognize physical accessibility as an important factor affecting landscape development. The definitions and scope of the accessibility concept vary. Sometimes, the concept used in transportation analysis is narrowed to the physical access [13]. Other times, the concept is more general including geographic as well as social and economic context [14]. Another group of researchers focuses on a very broad meaning of landscape accessibility incorporating social construction of space, institutional rights regimes, power strategies and values $[15,16]$. However, most of the accessibility research refers to urban context while Geo-mining heritage appertains to a rural landscape. These two drastically are different in the spatial-economic distribution of people's activities. For this reason, this paper examined how existent approaches and variables of accessibility are applicable in low-density, Geo-mining heritage settings.

In this scenario, this paper contributes to a wider framework of a research project named "TSulky" (Tourism and Sustainability in Sulcis-Iglesiente area), currently in progress, regarding the accessibility of the Iglesiente area. The Autonomous Region of Sardinia under the extraordinary "Sulcis Plan" funds ten selected research projects in the fields of energy, environment and culture. The plan acts as a development strategy that systematizes different regional planning instruments within a unitary and 
integrated vision. Resources were disbursed for 1.3 million euros based on agreements signed with universities, research bodies and private sector [17]. "TSulky" project joins three units of researchers from the Universities of Cagliari and Sassari: Depts. of Civil Engineering, Environmental and Architecture (DICAAR); Electrical and Electronic Engineering (DIEE), Architecture, Design and Urban Planning (DADU). The project is aimed at strengthening, organizing and managing the information on cultural and Geo-environmental resources linked by the mining identity. The "TSulky" project is structured in specific consequential phases and Work packages, to be logically faced in an iterative and incremental way and to organize the management of project activities. The first phase is the recognition of information about the Iglesiente area already available in official databases or in archives. The second phase is the definition of the criteria for the selection and representation of data and information with the aim to activate and implement a dynamic process of acquiring knowledge, coherently with the identification of the profile and specific interests of different stakeholders about resources. The third phase is aimed at defining the contents which, by specifically supporting the accessibility of the Iglesiente area for different types of users, favour the generation of a bi-directional information flow amongst local communities and administration, companies and service users. The results will lead to the design and implementation of an interpretative tool to facilitate the accessibility of the area, able to recognize the relational and dissemination potential of the reference nodes for the Iglesiente accessibility system, with the support of Artificial Intelligence/Web-based knowledge and mobility services in close cooperation with the local networks. The last phase will provide knowledge dissemination.

The research project combines a traditional, historical-materialist approach of accessibility in terms of physical access to goods, services and destinations, with the post-structural discourses and structured material options of living in terms of connective spaces and opportunities for a different level of socio-cultural interactions (e.g., practices of use, stakeholders involved etc.). It includes stakeholders in the possible development process and their practices of everyday life. In this sense, accessibility is an interpretative device for the organization of the knowledge about territory, as well as a driver for converting the marginal character of this area. The interpretative framework for landscape knowledge and accessibility facilitates access to information and services, both for the inhabitants and for visitors, according to a permanent and replicable program. The framework is organized according to knowledge (both, real and virtual, including geological, environmental, cultural, etc.) and user types (age, base, skills, interests, etc.). Three categories of accessibility nodes represent the territorial network: physical, functional and socio-cultural. Nodes of functional and socio-cultural accessibility are defined by means of attributes and first measurements are to come soon. In another sense, the perspectives of each place will depend on the ability to offer different opportunities and forms of comparative advantage on the accessibility to resources. Note that this paper focuses on the identification of physical accessibility requirements of nodes and connections amongst them, as well as exceptions from the standard accessibility approach.

The structure of this paper is divided into two parts. In the first part, it highlights spatial accessibility-based approaches and variables. In heritage settings, landscape accessibility goes beyond physical links and determinants of heritage places. This results in two principal directions of the paper outputs. Firstly, accessibility in Geo-mining heritage settings requires a qualitative assessment prior to the measurement. Both tangible and intangible heritage composition represents a physical environment that influences physical activity (walking, cycling and non-motorized transport) and mobility in the heritage area in general. Landscape accessibility and knowledge in Geo-mining heritage settings depend on the thematic relationships among tangible and intangible heritage. Thematic routes are parallel with physical and they recede the proximity of settlement or density of built structures. Thus, definition and qualitative assessment of general context come first as a variable of accessibility. Secondly, a quantitative measure of accessibility should not bound the qualitative assessment of features and elements. The universal value of the Geo-mining heritage is the territorial continuity of mining activity. Accordingly, mining activity should be the determinant for the definition of the scale while defining the local and regional level. Based on outputs from the first part of the paper, 
the second part of the paper proposed a methodological and interpretative framework for accessibility to the Iglesiente area. Although not comprehensive, a qualitative theoretical model aims to define the requirements of accessibility and to become the main developmental strategy in the Iglesiente heritage setting. Modifications or confirmation of the model is expected due to its later implementation.

\section{Methods}

The methodology used in this paper has a multi-disciplinary character, forming an outline and theoretical framework of the research. The research combined strategy and mixed-methods approach $[18,19]$. The elaborations of the transformative paradigm theory commonly use the mixed method in research [18]. Procedures of the mixed method included: qualitative and quantitative data collection, analysis and elaboration of both forms of data. They also added two forms of data that are integrated, merged, connected and embedded [18]. This qualitative and pragmatically oriented research initially determines problematic, potentials and resources of the local context that should be incorporated in territorial sustainable development strategies. The research determines problems and specificities of the context primarily and method subsequently. Taking into account the general research framework in this phase, literature overview and open-ended observations precede closed-end measures. In several stages of the research, we used the content analysis method in order to enable systematization of the key elements of the analysis. The conceptual framework of the research has been developed as the literature review and chosen from the scientific article databases by searching for the terms 'Accessibility,' 'Active Mobility,' 'Heritage Accessibility,' 'Heritage Models.' Furthermore, the findings are supplemented by relating literature following the most important heritage conventions, contemporary discussions and recommendations in relation to sustainable development, territorial development, urban planning, cultural landscape and documentation about Geo-mining heritage. The content analysis method also included analysis of primary documents (e.g., plans and official reports) and secondary sources (e.g., books, articles and relevant websites).

Thematic (Geo-mining heritage) and context specificities research included elements of the case study research method $[20,21]$ and direct observations [22] for empirical evidence. The case study as a qualitative method does not mean it is less strict than the quantitative method; indeed, it allows a closer view to the researcher [21]. The case study research employed a review of primary and secondary sources (plans, strategies, reports, as well as the written material on this topic). Direct observation method was used during multiple field study trips, included site investigation and visual mapping analysis of the first-hand experience, as well as verification of some desk analysis.

All previously mentioned methods are carried out paralleled. The research process was iterative. The interpretative framework for landscape accessibility and knowledge suggests the method for the selection of observations and measures. It starts with the description and clarification of the system (territorial logic). Then, the definition of the boundaries and components of the system due to people's activities and the physical environment. The boundaries of the system refer to a physical scale expressing at least dual character defined through the inside environment (the local scale of a heritage place, the nodes) and outside environment (the territorial matrix of nodes).

The findings of the research are inputs for the next phase and could be modified due to adjustments required by the implementation phase to come; this is a draft of the methodological framework for the research in progress. With reference to the following phases, the combination of Artificial Intelligence/Web-based knowledge can report both the access and the use of local resources for different types of users. The recourse to effective tools of analysis, communication and data sharing, with the possibility to pinpoint the information on free editable maps by direct experiences of the users, facilitates landscape accessibility and knowledge learning. It also allows comparing the fieldwork findings of accessibility attributes of the nodes to better understand the multi-dimensional, multi-scaled and multi-sectoral nature of the network connections. This paper positions in the second quarter of the complex research process of the annual project but its findings are the first theoretical inputs about physical accessibility. 


\section{Requirements of Landscape Accessibility in Geo-Mining Heritage Settings}

This section discusses the principles and variables of accessibility based on the spatial distribution and thematic orientation of heritage places. It elaborates theoretical findings and good practices relevant to the Geo-mining heritage context and low urbanity. Firstly, the research delineates visioning and planning on multiple scales (local and supra-local.) essential for more sustainable development and accessibility to sites with multiple values. Secondly, networking principles for scattered heritage sites are argued including a possible adaptation of good, real-world practice for the Geo-mining context. Thirdly, the section confronts the determinants of active mobility with the context of low-urbanized heritage settings.

\subsection{Multi-Scaled Accessibility}

The "European Spatial Planning Observation Network" - “ESPON" policy (2016) about territorial condition requires 'polycentric development' as fundamental for sustainable development. This is a place-based and integrated approach, which is based upon broader terms beyond the merely economic one [23]. Research done by "ESPON" (mapping the 'polycentricity' in Europe) illustrates the Iglesiente area with a positive urban structure composed of small and medium-sized towns. Their functional urban area has a dual, local and regional character. The lack of an organized system of mobility and information, capable of attracting different categories of users, as well as being a problem for the development of the territory, influences the emergence of opportunities, especially in inland areas with low-density settlements. Meanwhile, territorial cooperation of Iglesiente area has low range and intensity. "ESPON" (2016) policy recommendations conclude that the lower density implies more cooperation [23]. Cooperation practice and functional flows of enhancing polycentric development strengthen the interaction between bigger and smaller cities while acting parallel at the regional and local scale. Based on these guidelines, the inextricable link connects various possibilities of knowing, accessing and acting, therefore, benefitting from the physical and functional connections among places. In this sense, local development is linked above all to the configuration of space, the organization of systems, existing or developing networks of relationships and urban and infrastructural services and to the characteristics and knowledge of local communities. This networking aspect is crucial for heritage places as an integral part of the living environment.

After all, local context is dominant, and it conditions regional development strategies due to the internal environment of heritage settings. In the heritage setting, the internal environment of local context defines the intersection of nature, low-density settlements and disperse heritage features of the remote territory. Connectivity among those elements of the internal environment ensures inner thematic routes. The access point(s) to an internal environment (e.g., extra-urban bus station) connects the same kind of other inner environments or shared thematic routes. Connecting the different internal environments, the system grows into a more or a less homogeneous network. Therefore, the interpretative framework for accessibility has to act on the dual level, local and supra-local.

\subsection{Accessibility and Networking: A Model of European Route of Industrial Heritage-"ERIH"}

Constructed to act as a guide system, "European Route of Industrial Heritage"-_"ERIH" started in 2008, based on German laws. Approximately 250 members from twenty-four European countries are members of the network. Italy is taking part with eleven members and one representative on the board of management. The network acts both in real life and virtually, it is developed for multiple communicational purposes. It is conceived as a kind of tourism brand while understanding the industrial tourism, not as a niche market but "a broad movement inspiring many people" [24]. The "ERIH" supports innovative solutions and provides relevant information about the regeneration processes of old industrial areas and their accessibility. The main goal of networking activities is the development of vulnerable regions, with economic decline as a prevalent feature (including cross-border collaborations). "ERIH" networking model uses principles based on the spatial distribution and 
thematic orientation of heritage places. This research follows this topic-specific example of good practice and its networking principles for the construction of the interpretative framework for landscape accessibility and sharing knowledge about heritage.

The "ERIH" system has three conceptual elements: Anchor Points, Regional Routes and Theme Routes [24]. Firstly, Anchor Points represent the main module. These are important places for the exceptional historical value of European Industrial Heritage. They are considered as 'Focuses,' to be recognized inside and outside the site. They are the cornerstone of the whole system because they act as the starting points for various regional routes. Following the "ERIH" philosophy, there is a commitment list for Anchor Points. An ideal Anchor Point has to offer an imaginative interpretation of the site, while encompassing exhibitions, cultural events and other nearby attractions. Furthermore, it must fulfil the visitor's expectations regarding up-to-date tourism infrastructure and services. Secondly, Regional Routes are composed of Anchor Points that act as nodes within the proper territory that represent a single character of heritage. Linked landscapes form the territory by Regional Routes and sites with a specific characteristic(s). After all, what happens if one tries to observe the "ERIH" system as a possibility for the internal organization of a heritage territory? By scaling-down, the system from Europe to lower dimension, the territorial matrix and its elements (Regional Routes, Thematic Routes and Anchor Points) continue to follow networking principles of heritage. Besides, this approach is congruent with the 'polycentric' and multi-scale development.

\subsection{Active Mobility in the Low-Urbanized Heritage Settings: From Regional to Local Route and Vice Versa}

The active mobility, previously known as "Slow or Soft Mobility," has increased scientific interest within different disciplines from the 1970s-80s [25]. Perspectives, parameters and terms of detail about the concept of active mobility vary. Research with a diverse nature comprehend policymaking, transportation plans and urban planning [26], travel behaviour and public health research [27,28]. In general, active mobility research investigates the quality of life thought relations between the built environment and people's activity. These performances measures provide insights about influences and interactions between the built environment and physical activity (walking, cycling behaviour and not motorized activity). One significant aspect of the built environment is accessibility; spatial distribution of available destinations as places where opportunities are located [18]. Based on their methodologies and computational similarities, Vale et al. (2017) proposed four major categories (plus one) of place-based accessibility measures: (i) gravity-based (attraction-accessibility or potential); (ii) topology-based, which include topological measures of the network or infrastructure; (iii) distance-based, which include analyses of the closest facilities, (iv) walkability and walk score-type measures and (v) utility-based (benefits measures). However, the predecessor "Behavioural Model of Environment" [28] explains that the built environment shapes accessibility in terms of three components-origins and destinations, route characteristics of the trip and the characteristics of the area around origins and destinations. Another group of approaches to the accessibility is people-oriented measures (dis/abilities, preferences, attitudes and lifestyles that shape physic activity). People-oriented measures are more subjective than place-oriented measures (these measures are objective).

Analysis and characterization of built environment use a range of variables. Choi (2012) argues that previous research in the field of transportation and urban planning demonstrated a positive association between physical activity and the presence of mixed land uses (proximity/distance of assorted attractions) [29]. Furthermore, better connectivity (route options and quality of travel) and higher density positively correlate to physical activity (population density is amongst the most consistent positive associations of walking trips). The author highlights that variety of land uses, connectivity and density are factors that are manageable on various scales, while some others (e.g., quality of the route) are applicable only on small-scale urban design and also debates that urban design studies frequently include factors that relate to the condition and aesthetic (perceptual qualities). Statistically, these factors have no constant measures [29] but urban design studies did not attempt to measure perceptual qualities objectively. Instead of measuring, urban design research simply asserts 
the importance of perceptual qualities [30]. The additional basic factor to the built environment is the general urban context and all the measures must be calibrated to the context [29]. Likewise, active mobility proves an effective potential to base urban development strategies that increase the quality of urban space and people's quality of life [31]. Unfortunately, adequate infrastructure and positive environments are not enough. Implementation and success of the active mobility ideas in the development strategies also require encouragement strategies for different social groups and the promotion of active mobility [32].

Previous findings of the active mobility concept opened a dialogue for (re)definition of the relationships among built environment variables affecting active mobility. Preceding the establishment of a conceptual framework, a model demands an adaptation to the context of low-urbanized heritage setting. The adaptation demands redefinition of landscape features and elements as variables that overlap and collide within a specific built environment of Geo-mining heritage settings (dependent variables). We need also to identify and measure the elements that hinder or limit mobility and to reveal the possibilities of connecting and reaching places, making them effectively available for different users.

Above all, the framework has to clarify and describe the land uses, density and factors of perceptual qualities that ensure knowledge about the landscape in the heritage environment. Despite the fact that non-motorized transport is favourable, the spaciousness of geo-mining heritage requires the inclusion of all transportation modes in the accessibility model. Restriction to active mobility is advantageous on the local level. Moreover, all variables mentioned above concern the characteristics of the built environment, while perceptual qualities also depend on the properties of place from people' perspective (independent variables). Findings by environmental psychologists [33,34] explain that the people's perspective attaches environmental perception and cognition. They are generated from the personal expression of place and the meaning of place recognized by people. Melting the limits between dependent and independent variables, perceptual qualities are among the crucial variables of people's activities. Perceptual qualities are another vital aspect of the conceptual framework of this research. Further development of this paper hypothesizes people-related variables that are characteristic of heritage settings in the Iglesiente area. This includes both perspectives, visitors and people who live in this place. The perspective differs in the motive of physical activity, which could be transportation or leisure. This does not mean that visitors' motive is exclusively leisure, nor that just transportation motivates inhabitants to walk/cycle. The promotional activities about active mobility come secondary compared to the definition of the built environment and people-oriented variables.

Previous findings demonstrated principal concepts of landscape accessibility in the Geo-mining heritage settings. Landscape accessibility in the context of heritage settings, we noted, need to adopt a different approach. We summarized, in Figure 1 below, key findings of landscape accessibility and planning. The figure expressed the differences between the stand accessibility approach and variables and that of the Geo-mining heritage. The figure illustrates physical features, environmental qualities and individual reaction in accessibility approach. Firstly, individual reactions, as stated before in the text, is a highly subjective category and it has to be calculated in view of the specific target group (inhabitants and tourists). Secondly, environmental qualities rely on the objective appearance of the space configuration but they are dependable on the subjective capacity to perceive the space (aesthetics are individual to a certain degree). Environmental qualities, in any case, have high importance in heritage settings. They have to represent eminently the landscape knowledge of the Geo-mining heritage. Thirdly, pictured through implicit and explicit variables, physical features are the most objective among these three categories. Nonetheless, physical features and variables are about the built environment. Implicit variables, in particular, have to be adapted for the specific Geo-mining heritage settings. For this reason, the design of the methodological framework for landscape accessibility in geo-mining heritage settings prioritize characteristics of general context and the definition of the environmental settings. 


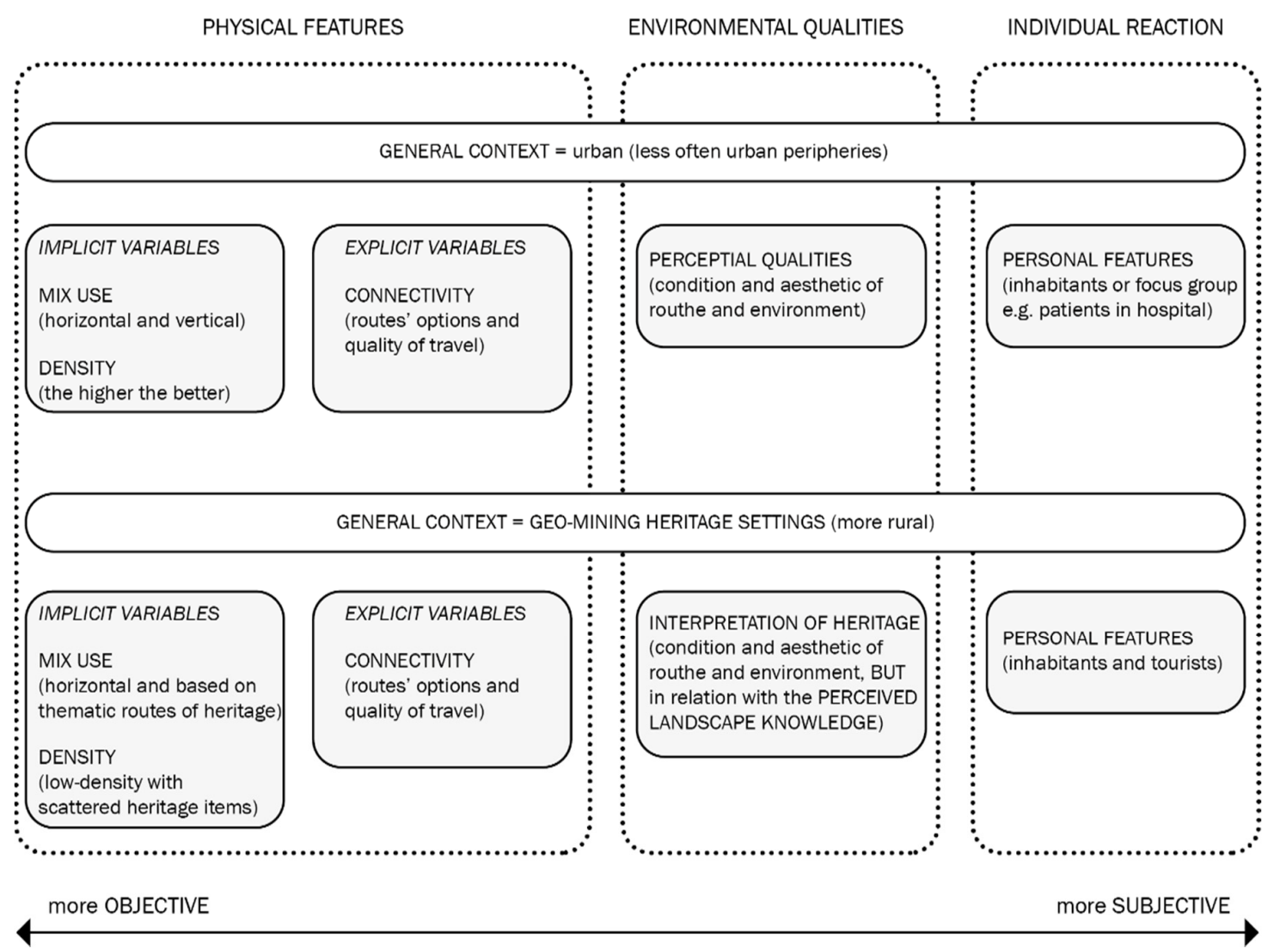

Figure 1. Summary of the key elements and findings from accessibility concept: A comparison between standard approaches features and those of the Geo-mining heritage settings (authors).

\section{A Methodological Framework for Landscape Accessibility in Geo-Mining Heritage Settings and Those of the Iglesiente Area}

Previous findings of landscape accessibility in the Geo-mining heritage settings, served as an input, supported the construction of the methodological frameworks. The proposed methodological framework excludes variables and highlights the definition of the environmental settings as the first step to be done. Consequently, in this section, the Iglesiente area of Sardinian Geo-mining Park has been introduced. The literature review has demonstrated that the improvement of the Iglesiente area requires a co-planning tool different from fixed territorial coordination. Thus, although not comprehensive, we applied a previously proposed methodological framework for the Iglesiente area. The definition of environmental settings narrowed the research area and specified the system boundaries. Application of this step alone is adequate to the stage of the "TSulky" project and the economy of this research. The framework still lacks empirical results so far because the detailed attribution of nods is the next step of the current "TSulky" project. Then, the evaluation to come could change the variables.

\subsection{The Interpretative Framework for Landscape Accessibility in Geo-Mining Heritage Settings}

Funded in the concepts of multi-scale accessibility, 'polycentric development' and networking principles of heritage, we proposed an interpretative framework for landscape accessibility and knowledge. Landscape dynamics of Geo-mining heritage asserts not only historical landscape memory but also the current condition of the place and territorial organizational perimeters. The place-specific situation should highlight the types of accessibility nodes and their combinations. The design of the territorial matrix of accessible and strategic places opens favourable opportunities for the involvement of the internal territories which brought the contiguity through the nodes of the matrix. Furthermore, prevalently rural, low-density settlements characterize geo-mining heritage settings. The linkage of the small hamlets and rural residential areas with the anchors situated in inhabited 
structures, services and supports facilities, offers an innovative sustainable development perspective based on the landscape accessibility and knowledge. It merges Geo-mining heritage components and other local and territorial resources contributing to the territorial sustainability by enhancing the public spaces and representative places [6]. Thus, the logic is applicable to diverse spheres. On the one hand, it serves environmental restoration (recovery and safety of physical structures and soft landscape). On the other hand, it serves reuse of physical structures, hard landscapes and path patterns related to the mining landscape memory [6].

The interpretative framework, we proposed in Figures 2 and 3, provides a territorial matrix of strategic places based on the relationships of reciprocal influence and conditioning between the nodes of the network. This logic structures the territory and directs its future organization to different scales. In this term, accessibility promotes a logic of territorial equity and cohesion in which some situations take on the value of urban centrality, while others rediscover their generative natural and cultural values. The method for the selection of observations and measures that should be carried out starts with the definition of the system (territorial logic), its boundaries and components due to people's activities and physical environment. The boundaries of the system refer to a physical scale expressing at least dual character defined through the inside environment (the local scale of a heritage place, the nodes) and outside environment (the territorial matrix of nodes). Three types of accessibility nodes organize the territorial networks and environments: Physical, Functional and Social-cultural. In this term, landscape accessibility and knowledge framework promote itineraries and interventions that make accessible, connect and organize the contemporary life of the places, offering advantages of greater liveability and usability. Nevertheless, it lays the basis for new forms of citizenship involving permanent and temporary populations or visitors.

Figure 2 exemplify, through three different stages, development steps of the interpretative and methodological framework for landscape accessibility in Geo-mining heritage settings. Illustrated stages merge key principles of 'polycentric development' with the context of heritage and principles proposed by "ERIH". Internal and external environments are defined in overlap of those principles. However, it is fundamental to observe and map all highlighted principles parallel.

Figure 3 illustrates the components and relationships of the proposed model, the inside and outside environment. Boundaries of the system observed are represented by: (a) External Transport and External Access Hubs to the settlements (and Geo-mining heritage features); (b) Internal Connectivity to the settlement, urban functions and heritage features (these include internal paths in the network sub-systems); and (c) Functional Hubs/Nodes (uses and attractions).

Both, external and internal environments presuppose tangible and intangible mining heritage features as omnipresent landscape matrix, which merges past and present (maximizing the dissemination of knowledge landscape in geo-mining heritage). More research is needed about multiple heritage values, components and attributes of Geo-mining heritage elements for singular sites.

External access hubs and internal connectivity subnetwork systems equally concern inhabitants and visitors, whilst frequency and motives vary. The accessibility to heritage places intended for recreational activities should ensure equal opportunities, human rights, security and well-being. Accessibility within a heritage landscape concerns performances such as ease of getting around, comfort, security and the maximum degree of autonomy possible for everyone. These performances improve the quality of the visitors' experience of the heritage place. Different environments or types of communities offer different opportunities and challenges for promoting walking/cycling. More research is needed about perceptual qualities of the environmental accessibility model to balance the opportunities for both, inhabitants and visitors. In the Geo-mining heritage context, perceptual qualities. 
POLYCENTRIC DEVELOPMENT MULTI-SCALE ACCESSIBILITY

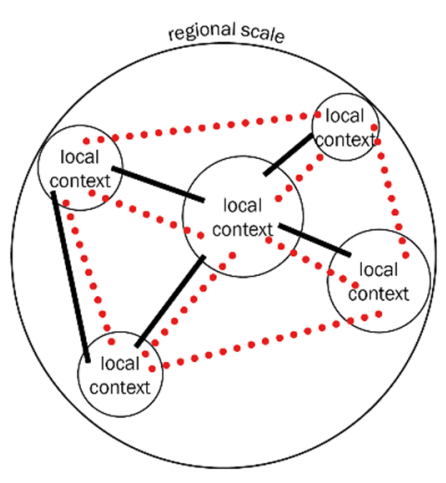

- physical connections

-.... functional connections
MULTI-SCALE ACCESSIBILITY IN THE GEO-MINING HERITAGE SETTINGS

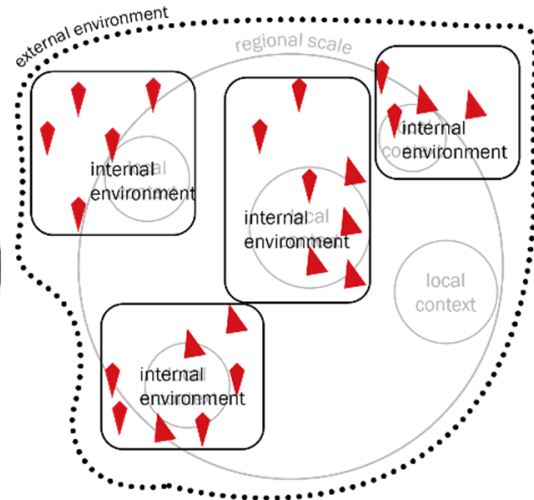

$1 \Delta$ heritage items

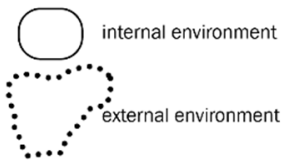

REGIONAL ROUTES, THEMATIC ROUTES AND ANCHOR POINTS IN THE GEO-MINING HERITAGE SETTINGS
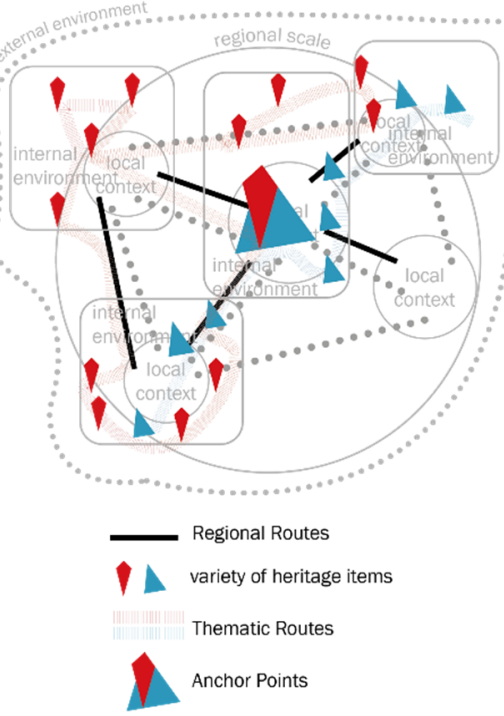

Figure 2. The development steps of the interpretative and methodological framework for landscape accessibility in Geo-mining heritage settings.

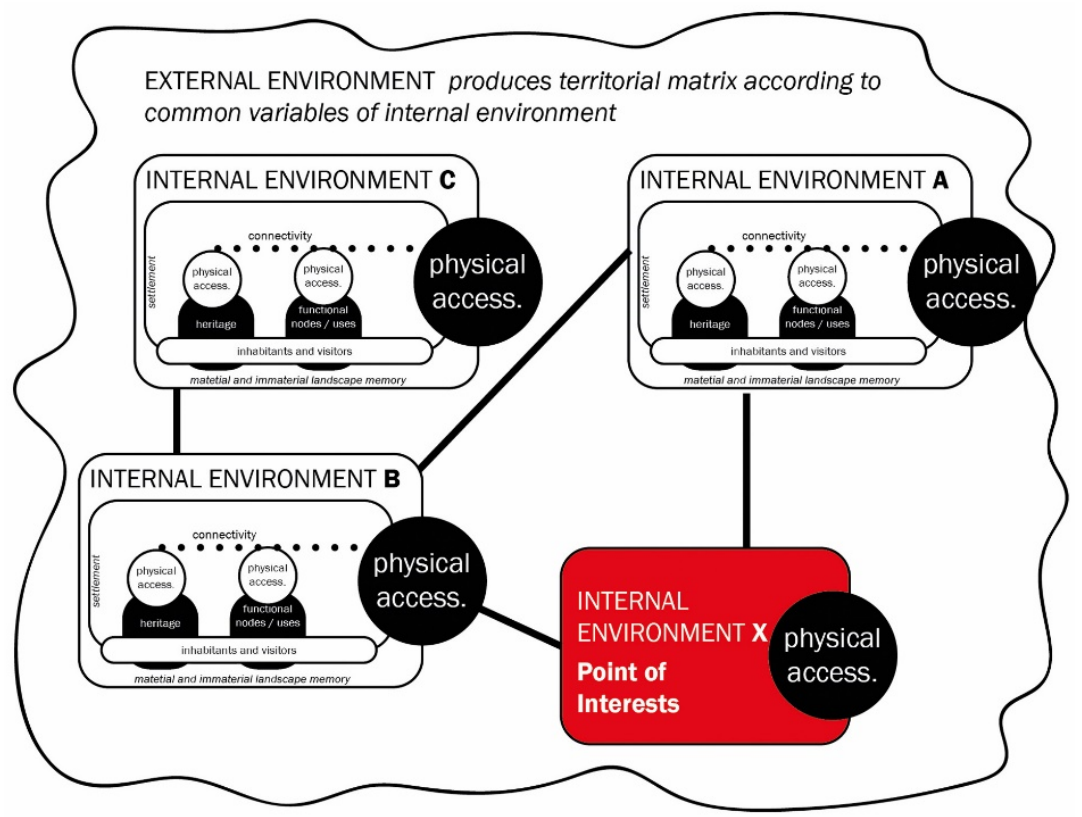

(a) External Environment

Figure 3. Cont. 


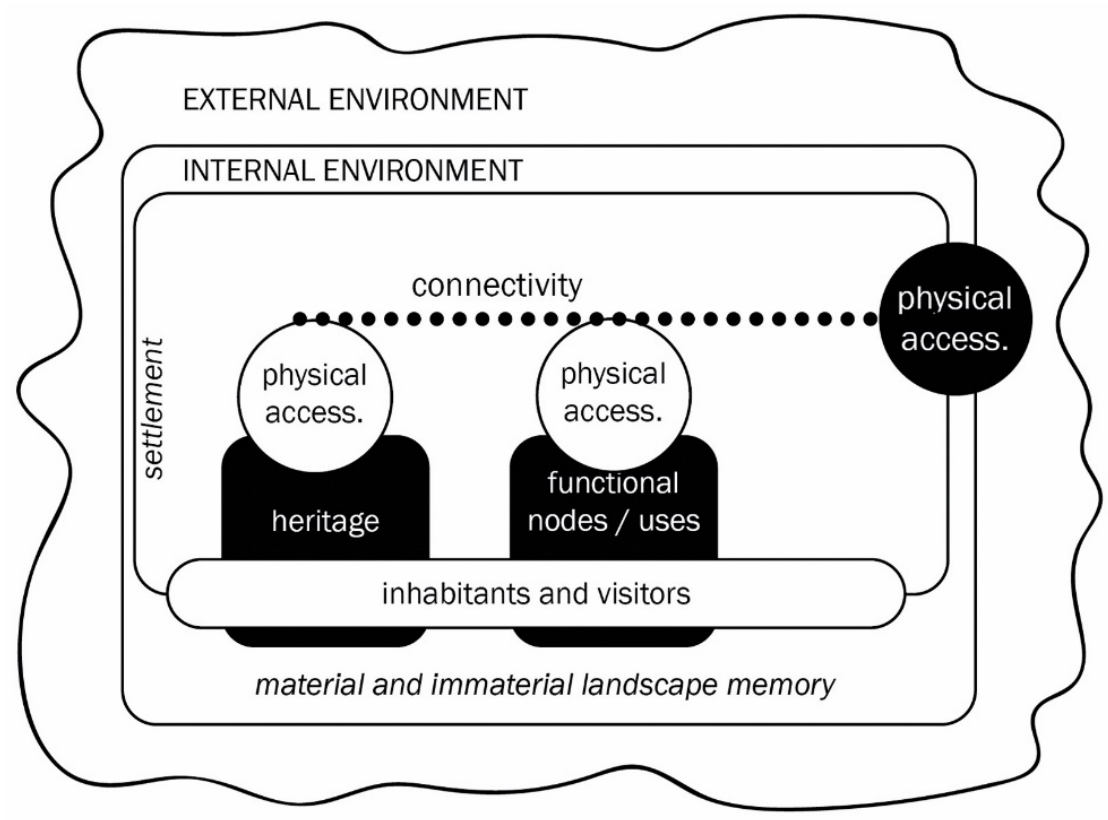

(b) Internal Environment

Figure 3. The proposed Environmental model: (a) External environment produces a territorial matrix linking the common variables of the internal environment. Some parts of the internal environment could have a more developed or important variable than the other parts. In this case, the internal environment becomes 'point of interest' or reference spot for the examined variable, anchor point of the territorial matrix. (b) Internal environment scheme lists the components of the nodes that have to be accessible from the outside environment and within the inside environment.

\subsection{The Context of the Iglesiente Area}

Iglesiente area is part of the Geo-mining Park in Sardinian Island proclaimed by "UNESCO" for a heritage of great importance in 1997. Opposing the great potentials and unique heritage values, the Iglesiente area (and complete Sardinian Geo-mining Park) still faces a deep post-mining crisis. This fact places the Iglesiente area among the less developed ones in Sardinia. The whole Region of Sardinia has a negative natural balance and decreasing population tendency [35]. The area of Iglesias is highly influenced by Regional standards. The density of population is extremely low. For example, Fluminimaggiore 108.18, Iglesias 128.6 and Buggerru has 21.9 inhabitants per square km compared to the average regional value of 68 inhabitants per square $\mathrm{km} \mathrm{[36].} \mathrm{The} \mathrm{predominance} \mathrm{of} \mathrm{data} \mathrm{about}$ Cagliari in Regional average value (346 inhabitants per square $\mathrm{km}$ ) is not negligible fact. At the same time, there are negative trends of immigration and the high rate of unemployment at the Iglesiente. The prevalent economic activities concern the tertiary sector (scarce in relation to the other provinces), the industry (petrochemistry mostly) and finally agriculture [37].

Starting with "Technical and Economic Feasibility Study" of the Sardinian Geo-mining Park (2002), some authors continued to express the necessity for plan guided by the 'hierarchy' in coordination $[2,3,38]$. The plan aims to stop the economic stagnation and decrease of the population while celebrating the territorial prosperity and growth. The documentation urges the need for planning of the regional development exclusive to authoritative programming and projecting. Alongside the development process, such as programming and projecting should take care of heritage space. This led to conclude that the Geo-mining Park necessitates a new theoretical framework to ensure branding and placement of the complete territorial system due to its heritage character, while management and promotion must ensure liveability first and visibility afterwards. Ever since the heritage proclamation, sustainable planning development tools remain the unfulfilled goal of the Iglesiente area. A suchlike tool has distinct strategic priorities based on local resources and unique governance for the harmony 
and balance among different scales. It presupposes recognition, categorization and linkage between determined landscape components. The links between heritage components and territorial equity are prescribed in the landscape memory (signs, visual order and 'urban codes' of Geo-mining heritage landscape), and still, we have to reveal and interpret them [6].

\subsection{The Definition of the Environments and System Boundaries of the Iglesiente Area}

The area of Iglesiente is not administrative but an organizational unit of former mineral extraction and Geo-morphological configuration of the lands. This fact makes the borders of the Iglesiente invisible, yet precisely defined for those who 'live in the territory.' Located in south-west Sardinia, the Iglesiente area celebrates the universal value of the homogenous territory of the historical and geographical sub-regions of Sulcis-Iglesiente-Guspinese, characterized by intensive extraction activities. The Guspinese area has always functioned as independent, while Iglesiente belonged to the historical region of Sulcis. The Geo-morphological configuration divides the complex system of Sulcis into two basins: Metalliferous (Northern) and Carboniferous (Southern) [39]. These two basins defer in landscape modifications, due to the distinct process of mineral extraction and periods of active mining. This research implements its goals of the pilot project at the metalliferous basin of the Iglesiente. Accordingly, the first task to accomplish with the interpretative framework is the definition of the borders, buffer zone and/or the relationships that outline the area of Iglesiente and its boundaries of the territorial systems; external and internal environments. Potential difficulty in research is the fact that Iglesiente is not an administrative unit, whilst the statistical data are.

Evoking the landscape memories, the city of Iglesias has always been the administrative and functional centre of the area, created at the end of 1200, entirely depended on the mining economy. The mines and the buildings that served them raised in its surroundings, facing the urban centre and grouped in isolated neighbourhoods. Functional organization of the city provided that industrial buildings are clearly distinct from the civil ones. Everything was structured according to the work and the control of the workers, following the morphological characteristics of the territory. Over years, serving as a reference point for all the surrounding mining villages, Iglesias acquired a leading role as a city centre [38].

The functional organization of the mineral extraction (concessions on the property and the extraction, transportation and primary elaboration of the minerals) caused territorial dependence among the settlements and surrounding areas. Two arrangements appeared within the Iglesiente metalliferous basin. First, the southern area that interrelates the settlement of Guspini with Iglesias. Second, the northern area has two sub-organizational perimeters. The coastal and inland units compose two sub-organizational sections of the northern Iglesiente. The coastal unit spreads from Iglesias to Buggerru. The inland unit gathers together Iglesias and Fluminimaggiore. Drawing a territorial triangle, because of the transportation purposes, the inland unit relates to the seacoast (from Fluminimaggiore to Buggerru), too [39]. Aimed to examine the opposite conditions of the ex-mining settlements relating to the city of Iglesias, this research chooses to operate on the territory of the northern unit, both, coastal and inland. Considering the Geo-morphological relief configuration, these two units will also diverge because of the following two issues. Firstly, coastal settlements emerged for the mineral extraction purposes while inland settlements were converted from previous settlements with livestock and agriculture land uses to mining [6]. Secondly, the problem lies in the current administrative nature.

In the next steps, the research intends to analyse the position and role of the ex-mining settlements and their relationship with the accessibility scale. The first case takes into account the central position of the municipality of Fluminimaggiore (inland, former livestock settlement before the beginning of the mining). Another case is the settlement of Nebida that is part of the municipality of Iglesias (coastal ex-mining settlement constructed for the mining intent). The complex and peculiar territorial relationships require the inclusion of the coastal settlement of Buggerru that is linked in one way or another to the realities of Fluminimaggore and Nebida. This viewpoint does not solely reflect 
local specificities of administrative nature but the built environment and all features of daily life. The environmental context of Iglesiente outlines the municipal areas of Fluminimaggiore, Iglesias (as a referent municipality for Nebida) and Buggerru. Figure 4 represents: (a) the Iglesiente area within the National (Italy) and Regional (Sardinia) context and the Province of Carbonia-Iglesias with Sulcis-Iglesiente and Guspinese-Arburese areas of the Sardinian Geo-mining Park; (b) The three Municipalities of Iglesiente (Fluminimaggiore, Buggeru and Iglesias) as the area selected for the further step of applied research at the local scale. According to the suggestions of the methodological framework for landscape accessibility in Geo-mining heritage settings (proposed in the previous section), the next step will start with the mapping of the heritage components. The outputs of this step, still to come, will define precisely the internal and external environments.
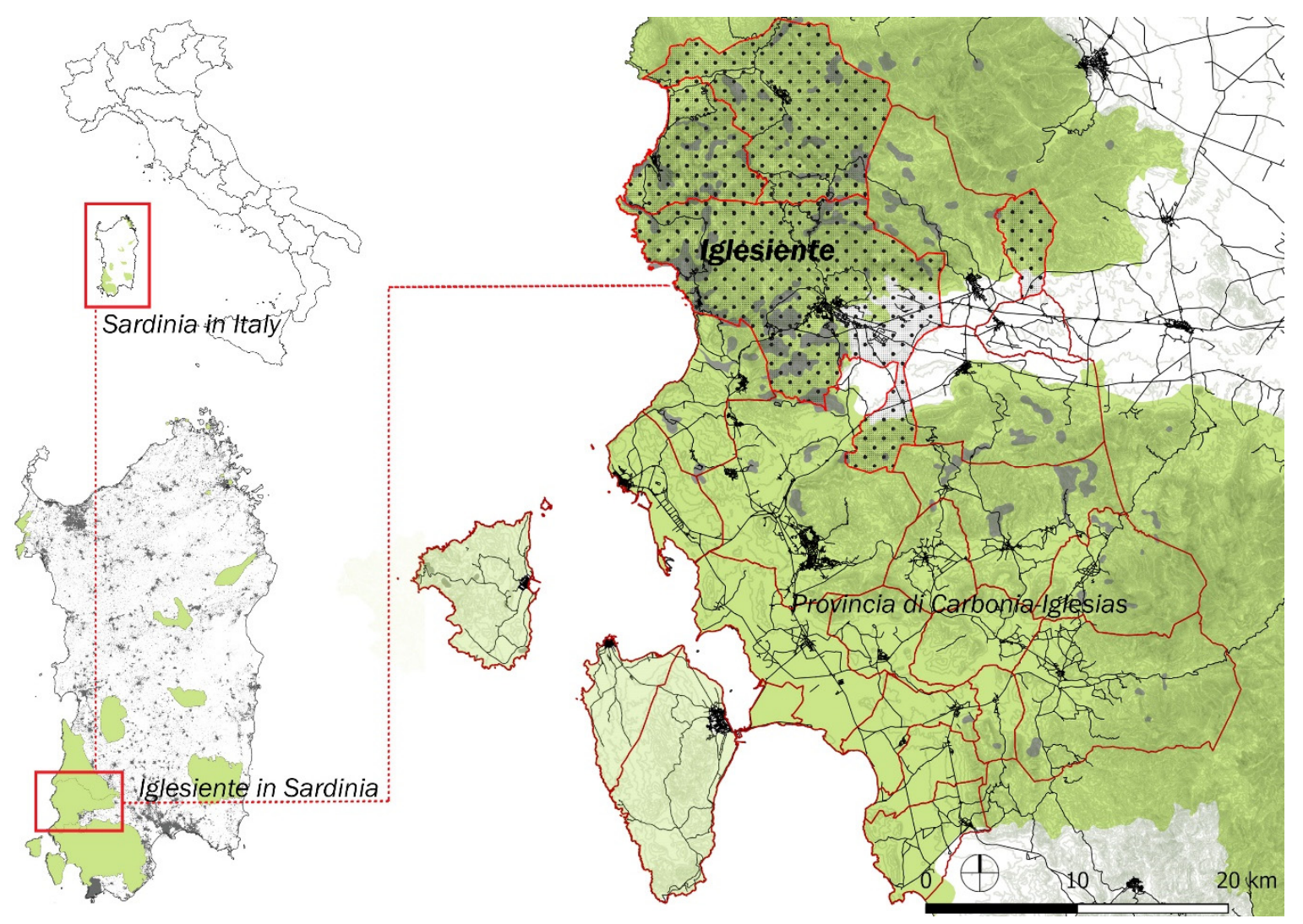

(a) Iglesiente area within the Province Carbonia-Iglesias and in National (Italy) and Regional

(Sardinia) Context

Figure 4. Cont. 


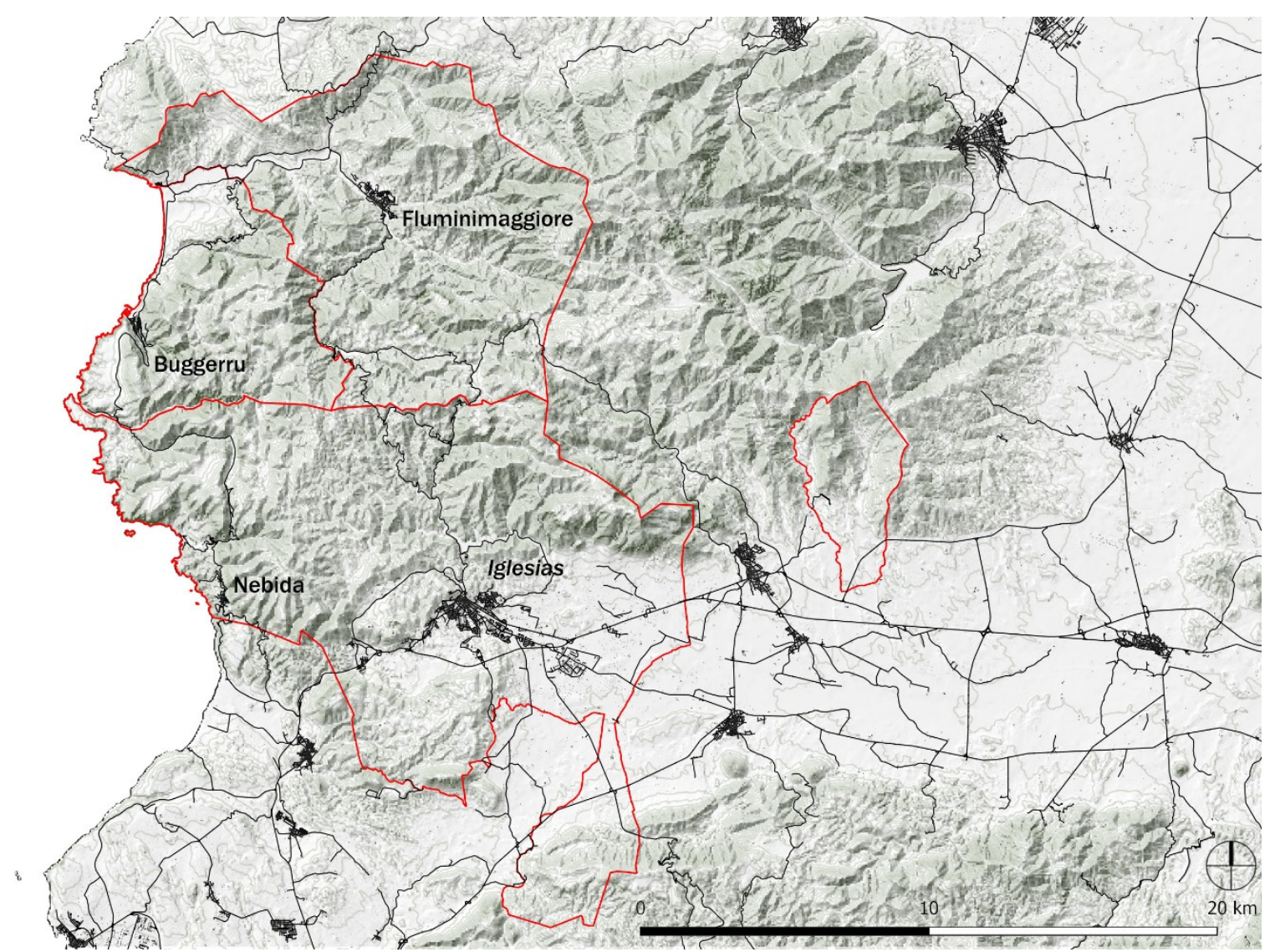

(b) Administrative limits of three selected settlements: Fluminimaggiore, Nebida (Municipality of Iglesias) and Buggerru

Figure 4. Context and Boundaries of the Iglesiente area: (a) Iglesiente area within the Province of the Carbonia-Iglesias and the Carbonia-Iglesiente and Guspinese-Arburese areas of the Geo-mining Park within the National (Italy) and Regional Context of the Geo-Mining Park in Sardinia; (b) Administrative limits of three selected settlements for further research: Fluminimaggiore, Nebida (Municipality of Iglesias) and Buggerru.

\subsection{Some Hypothesis about External Environment and Networking of the Iglesiente Heritage}

Based on previous findings, in the Geo-mining heritage settings, physical features (manifestations of the built environment and physical connections) and environmental qualities (perceptual qualities: condition and aesthetic) are dependable on heritage items. This conclusion prevents the precise definition of the internal and external environment. Correspondingly, the following text drafts some hypothesis about the networking of the Iglesiente heritage. Although not precise, the hypothesis extract the principles and main components for further research.

The Iglesiente area is particularly rich with items that permeate the whole territory with mining heritage; including mines, facilities and aspects related to their Millenary activity. It covers approximately $480 \mathrm{~km}^{2}$. In the same area, Iglesiente has the oldest Italian paleontological formations (Geological Heritage) and archaeological evidence since the Neolithic, Punic and Roman periods (historical heritage). An explicit and sophisticated interpretation of heritage values requires vast knowledge about the landscape, high deductive capacity and artistic interpretation. The essence of the Geo-mining heritage is the spatial continuity of the mining activity even though the items of the system can be physically distant [40]. Physical distance and spatial distribution of Geo-mining heritage (scattered and isolated heritage items over the landscape and underground) assume variant perception of information. Also, physical prerequisites of heritage items presume combination of transportation means to reach the items. Accordingly, planning and interpretative expression of heritage values must 
restore adequate knowledge and respond to a modality of active mobility. The knowledge to provide involves both, regionalization of experience and localization of identity and tradition; particular spaces at multiple scales [6]. Not only multiple scales but also these particular places have to demonstrate multiple values. Guided by a good example of practice in the field of networking the industrial heritage, we hypothesize "ERIH" networking principles at the area of Iglesiente. In this regard, if we scale down the "ERIH" system at the level of Sardinia, the first step would be distinguishing "key sites' and the second to establish two types of routes. Based on Regional Routes, Thematic Routes and Anchor Points, without deeper investigation of attributes, Figure 5 summarizes and illustrates the principle of networking applied in the case of the Iglesiente area of the Geo-mining Park in Sardinia.

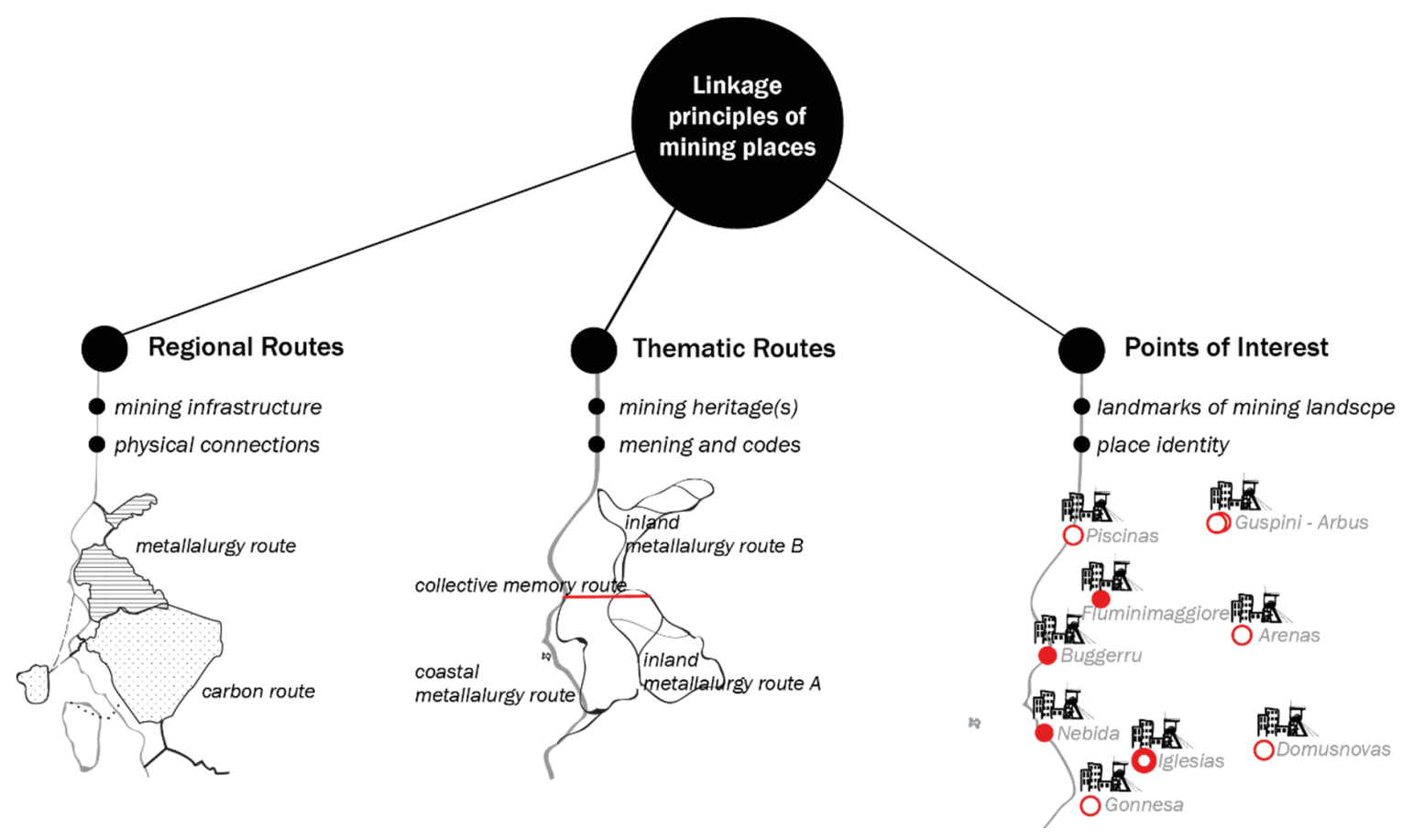

Figure 5. Proposed principles of linkage and networking within the external environment. Source: authors' elaboration of Beretić 2018.

Opposing the "ERIH" philosophy, we suggest Anchor Points defined at the end of the process. "Anchor points" are central to the whole system while acting as nodes where most of the possibilities overlap. Respectively, the selection and definition of Anchor Points appear after the attribution and characterization the whole system aimed to balance the liveable with a visible dimension of heritage places. Therewith, commitments proposed by "ERIH" philosophy must be enlarged with a functional and symbolic (socio-cultural) dimension of heritage places and a vital dimension of everyday life. Functional and socio-cultural dimensions are the subject of a complex "TSulky" project, but, go beyond the economics of this research.

\section{Final Remarks}

The Geo-mining heritage is a relatively new concept, missing literature about models for the revitalization and enhancement of heritage integral within the historical and cultural context [11]. This research proposes an interpretative methodological framework for accessibility as a crucial factor affecting the landscape development of Geo-mining heritage setting. Landscape accessibility is strictly interlaced with landscape knowledge about the heritage territory that illustrates different possibilities and opportunities for the fruition, use and management of the territory. The adoption of such a strategic approach presupposes a renewal of the tools and methods for the reading of heritage settings, so as well as to abandon sectoral visions and isolate and take an integrated view that is more appropriate to 
understand the multidimensional and intertwined nature of the processes and relationship among network elements. This is equivalent to constructing an interpretative device capable of restoring the relationship of mutual influence and conditioning between the nodes of the network, with which to manage the planning of initiatives in the area and customize, at the different scales, the planning interventions about cultural and geo-environmental resources.

The proposed interpretative model aims to reverse local and regional problematics. An interpretative device offers easier readability of heritage values and higher accessibility in terms of territorial cohesion. This research makes a part of a bigger, annual research project "TSulky" funded by the Region of Sardinia. This paper examined leading theories about physical accessibility and specificities of Geo-mining Parks, adequate for the elaborated case of Iglesiente area (Sardinia, Italy). In this research, we defined the system, boundaries and components of the environments as an integral part of the physical accessibility nodes in the Iglesiente area. In the context of the "TSulky" project (which this research belongs), nodes of functional and social-cultural accessibility are defined by means of attributes and first measurements that come in the next stage. Although not comprehensive due to measurements to come soon, a qualitative model address the prerequisites of accessibility to become the development strategy in the geo-mining heritage setting.

First, heritage context requires accessibility to the specific knowledge that represents the potential for the construction of thematic routes and boundaries, which draws new landscape patterns. These patterns come from immaterial past (knowledge about the heritage) but also from the tangible present because the sites with a common theme should be physically connected and accessible. Conservation, promotion and the sustainable development of Geo-mining heritage requires the interpretation and representation of knowledge about various Geo-morphological, socio-ecological, socio-cultural and perceptual specificities of the landscape. The complexities of fabric and dynamics in the trans-creation of knowledge of the landscape address a range of distinct interest groups: landscape practitioners, policy makers, managers (sectorial knowledge) and public [41]. The public is sub-divided into two groups of people. These people essentially need different information about heritage, local communities and visitors. Their motives to acquire information usually confront diverse motives to access the heritage. The visitors' first motive is leisure but that is not the case with inhabitants or and onsite interpretation has a specific message for a target group (departing knowledge, experience and sensibility of local people and visitors are not the same). On the local level, Geo-mining heritage sites have to express the scientific, educational and interpretative value. Interpretation is a way of conveying a particular message to a precise target group, 'the art of explaining the meaning and significance of sites visited by the public' [41]. Balancing the fruition of the local resources and Geo-heritage conservation, the interpretation is central to sustainable local development. The majority of visitors is motivated by aestheticism and escapism and "people usually visit the outdoors to socialize and relax rather than to learn" [41]. Therefore, interpretation of knowledge about the heritage shapes people's activities, as well as it frames the future of the place and quality of life. On the other hand, it defines features and elements of heritage that construct thematic routes. Deepened analyses of thematic routes of Iglesiente area is needed to illustrate the heritage mosaic.

Secondly, we would like to highlight a few exceptions from the standard accessibility approach. Reviewed literature about approaches to accessibility offers an introduction to the discursive concept of accessibility in heritage settings. Most of the literature intervened with an urban context distinct from the Geo-mining heritage settings by the spatial-economic distribution of people's activities. The fundamental difference in accessibility approach in Geo-mining heritage settings goes beyond spatial indicators, physical links and determinants of an urban context. For example, previous findings confirmed a positive correlation of mixed land use and higher density with physical [29] activity. These variables are comprehensible motivations in a small-scale urban context but irrelevant dependable variables for the low-density, spread and remote territory of Geo-mining heritage settings. In that respect, two principal issues affect physical accessibility measurements and selection variables while constructing the development model. Firstly, accessibility to landscape knowledge in Geo-mining 
heritage settings requires a qualitative assessment prior to the measurement. Both tangible and intangible heritage compositions are strictly connected to the physical environment that influences physical activity (walking, cycling and non-motorized transport) and mobility in the heritage area in general. The accessibility in geo-mining heritage settings depends on thematic relationships among tangible and intangible heritage parallel with physical routes and prior to the proximity of settlement or density of built structures. Thus, definition and qualitative assessment of general context come first as a variable of accessibility. Secondly, a quantitative measure of accessibility must not bound the qualitative assessment of features and elements. The universal value of the Geo-mining heritage is the territorial continuity of mining activity. Having said that, mining activity should be the determinant for the definition of the scale while defining local and regional level.

Thirdly, we would like to highlight the possibilities for application of the proposed model in this research. Low-density, spread and remote territory could be the general context for various rural areas around the world. Therefore, we could assume that the proposed logic of the territorial matrix and nodes applies in all low-density, spread and remote territories in need of polycentric, multi-scale development. Still, the interpretative model is conditioned by the singular heritage themes. The Geo-mining heritage territory differs from all the other heritage settings because it has embedded landscape memory of mining activity and it is responsible for representing the landscape knowledge according to an accessibility model for territorial cohesion. This contextual specificity of accessibility applies in similar cases of industrial and/or Geo-mineral heritage or any other heritage or its thematic unity. However, changes in the general thematic and landscape character directly request a variation in the interpretation of landscape knowledge. Accordingly, the accessibility model has to be changed.

Finally, the framework is not without its methodological problems. The main limitation of this research is the comprehensiveness of the proposed model due to the stage of "TSulky" project, currently in progress. This does not affect the construction, nor the logic of the model itself but it might change the intensity and hierarchy among some links and physical routes. Nevertheless, it is useful as a planning instrument to understand and plan accessibility in low urbanized spatial settings in terms of land use, mobility and services. Regardless of changes that may appear, this framework supports sustainable local development while conceiving the future of territorial identity that resulted from past and present peoples' activities.

Author Contributions: Conceptualization, N.B.; Methodology, N.B. and A.P.; Investigation, N.B.; Writing-Original Draft Preparation, N.B.; Writing-Review and Editing, N.B. and A.P.; Visualization, N.B.; Supervision, N.B. and A.P.; Project Administration, N.B. and A.P.

Funding: This research is conducted within the Tsulky research project. The Tsulky research project ("Tourism and Sustainability in Sulcis-Iglesiente area") was funded by Autonomous Region of Sardinia (within the Agreement for the management of fundamental or basic research projects for the implementation of interventions under the research for the "Sulcis Plan", CIPE Resolution n. 31 20.02.2015, and resolution n. 52/36 28.10.2015, “Sulcis Strategic project" - public-private research project), executive resolution n. 6525 register n. 666 14.09.2017. The APC was funded by the project chief scientist for the 3rd research unit, Alessandro Plaisant.

Conflicts of Interest: The authors declare no conflict of interest. The funders had no role in the design of the study; in the collection, analyses or interpretation of data; in the writing of the manuscript or in the decision to publish the results.

\section{References}

1. Wirth, W.; Černič-Mali, B.; Fischer, W. Introduction. In Post-Mining Regions in Central Europe. Problems, Potentials, Possibilities; Wirth, W., Černič-Mali, B., Fischer, W., Eds.; Oekom Verlag: München, Germany, 2012; pp. 14-27.

2. Perelli, P.; Pinna, P.; Sistu, G. Mining heritage, local development and territory identity. The case of Sardinia. In Mining Heritage and Tourism. A Global Synthesis, 1st ed.; Conlin, M.V., Jolliffe, L., Eds.; Taylor \& Francis Group: Abingdon, UK; Routledge: New York, NY, USA, 2011; pp. 203-213.

3. Parco Geominerario Storico Ambientale Della Sardegna. Available online: http://www.parcogeominerario.eu/ (accessed on 16 May 2014). 
4. Region of Sardinia. Carta di Cagliari. 1998. Available online: http://web.tiscali.it/perparcogeominerario/ carta_di_cagliari.htm (accessed on 15 April 2014).

5. Beretić, N.; Cecchini, A.; Plaisant, A.; Đukanović, Z. Glocal governance capacity. Mining heritage of Sardinia. Serbian Arch. J. Issue Local Gov. Sustain. Spat. Dev. 2015, 7, 299-316.

6. Beretić, N. Production of Space: Reproduction of Mining Landscape in Sardinia. Ph.D. Thesis, University of Sassari, Alghero, Italy, 2 March 2018.

7. Harvey, D. Heritage pasts and heritage presents: Temporality, meaning and the scope of heritage studies. Int. J. Herit. Stud. 2001, 7, 319-338. [CrossRef]

8. Mubaideen, S.; Kurdi, A.N. Heritage conservation and urban development: A supporting management model for the effective incorporation of archaeological sites in the planning process. J. Cult. Herit. 2017, 28, 117-128. [CrossRef]

9. Radosavljević, U.; Đorđević, A.; Lalović, K.; Živković, J.; Đukanović, Z. Nodes and Networks: The Generative Role of Cultural Heritage for Urban Revival in Kikinda. Sustainability 2019, 11, 2509. [CrossRef]

10. Locke, R.; Meha y, M.; Haas, T.; Olsson, K. Urban Heritage as a Generator of Landscapes: Building New Geographies from Post-Urban Decline in Detroit. Urban Sci. 2018, 2, 92. [CrossRef]

11. Obad Š'citaroci, M.; Bojanić Obad Š'citaroci, B. Models of Revitalisation and Enhancement of Cultural Heritage and Sustainable Use. In Cultural Urban Heritage. The Urban Book Series; Obad Š́citaroci, M., Bojanić Obad Š'citaroci, B., Mrđa, A., Eds.; Springer: Cham, Switzerland, 2019; pp. 457-475.

12. Antrop, M. Why landscapes of the past are important for the future. Landsc. Urban Plan. 2005, 70, 21-34. [CrossRef]

13. Burns, L.D.; Golob, T.F. The role of accessibility in basic transportation choice behavior. Transportation 1976, 5, 175-198. [CrossRef]

14. Farrington, J.H. The new narrative of accessibility: Its potential contribution to discourses in (transport) geography. J. Transp. Geogr. 2007, 15, 319-330. [CrossRef]

15. Semm, K.; Palang, H. Landscape accessibility: Spaces for accessibility or spaces for communication? Living Review. J. Landsc. Res. 2010, 4, 4. [CrossRef]

16. Sennett, R. The Fall of Public Man; Faber and Faber: London, UK, 1986.

17. Autonomous Region of Sardinia. Sulcis Plan. Available online: https://www.regione.sardegna.it/j/v/13?s= $347708 \& \mathrm{v}=2 \& \mathrm{c}=3 \& \mathrm{t}=1$ (accessed on 18 June 2019).

18. Creswell, J.W. Research Design: Qualitative and Quantitative Approaches; Sage Publication: Thousand Oaks, CA, USA, 1994.

19. Groat, L.N.; Wang, D. Architectural Research Methods; John Wiley \& Sons: Hoboken, NJ, USA, 2013.

20. Yin, R. Case Study Research: Design and Methods, 2nd ed.; Sage Publishing: Beverly Hills, CA, USA, 1994.

21. Flyvbjerg, B. Five Misunderstandings about Case-Study Research. Qual. Inq. 2006, 12, 219-245. [CrossRef]

22. Taylor-Powell, E.; Steele, S. Collecting evaluation data: Direct observation. In Program Development and Evaluation; University of Wisconsin-Extension: Madison, WI, USA, 1996; pp. 1-7.

23. ESPON. Policy Brief. Polycentric Territorial Structures and Territorial Cooperation; ESPON EGTC: Luxembourg, 2016.

24. European Route of Industrial Heritage. Available online: https://www.erih.net/fileadmin/Mediendatenbank/ Downloads/Membership-Forms_en/ERIH_Membership_Brochure.pdf (accessed on 27 June 2019).

25. Bahrami, F. Automobility Beyond Car Introducing a New Coordinate System for Transforming Urban Mobility; À La Faculté de L'environnement Naturel, Architectural et Construit Laboratoire D'urbanismE: Lausanne, Switzerland, 2017.

26. Achuthan, K.; Titheridge, H.; Mackett, R.L. Measuring pedestrian accessibility. In Proceedings of the Geographical Information Science Research UK Conference (GISRUK), Maynooth, UK, 11-13 April 2007; Winstanley, A.C., Ed.; Colgan Print and Design: Naas, UK, 2007.

27. Vale, D.S.; Saraiva, M.; Pereira, M. Active accessibility: A review of operational measures of walking and cycling accessibility. J. Transp. Land Use 2016, 9, 1-27. [CrossRef]

28. Moudon, A.V.; Lee, C. Walking and Bicycling: An Evaluation of Environmental Audit Instruments. Am. J. Health Promot. 2004, 18, 21-37. [CrossRef] [PubMed]

29. Choi, E. Walkability as an Urban Design Problem. Understanding the Activity of Walking in the Urban Environment. Ph.D. Thesis, KTH Royal Institute of Technology Architecture and the Built Environment School of Architecture, Stockholm, Sweden, 2012. 
30. Ewing, R.; Handy, S. Measuring the Unmeasurable: Urban Design Qualities Related to Walkability. J. Urban Des. 2009, 14, 65-84. [CrossRef]

31. Talen, E. Pedestrian Access as a Measure of Urban Quality. Plan. Pract. Res. 2002, 17, 257-278. [CrossRef]

32. Haufe, N.; Millonig, A.; Markvica, K. Developing Encouragement Strategies for Active Mobility. In Proceedings of the Transportation Research Procedia 19, International Scientific Conference on Mobility and Transport Transforming Urban Mobility, mobil.TUM, Munich, Germany, 6-7 June 2016; Elsevier B.V.: Amsterdam, The Netherlands, 2016.

33. Gifford, R. Introduction: Environmental Psychology and its Methods. In Research Methods for Environmental Psychology, 1st ed.; Gifford, R., Ed.; Wiley Blackwell: Malden, MA, USA; Oxford, UK, 2016; pp. 1-8.

34. Bell, S. Elements of Visual Design in the Landscape, 2nd ed.; Spon Press: London, UK; New York, NY, USA, 2004.

35. Cannaos, C.; Onni, G. Sardegna: Ad marginem. Arch. Urban Reg. Stud. 2017, 118, 29-49. [CrossRef]

36. Popolazione Residente al $1^{\circ}$ Gennaio. Available online: http://dati.istat.it/Index.aspx? DataSetCode=DCIS POPRES1 (accessed on 14 January 2019).

37. Beretić, N.; Cecchini, A.; Đukanović, Z. Geotourism as a Development Tool of the Geo-mining Park in Sardinia. Geoheritage 2019, 1-16. [CrossRef]

38. Mezzolani, S.; Simoncini, A. L' archeologia industrial. In Sardegna da Salvare. Storia, Paesaggi, Architetture delle Miniere, 3rd ed.; Mezzolani, S., Simoncini, A., Eds.; Archivio Fotografico Sardo: Nuoro, Itlay, 2007; pp. 11-20.

39. Ottelli, L.; Ottelli, L., Jr. Piccole Storie di Uomini e Miniere del Passato. Passeggiata nei Sentieri della Memoria del Sulcis-Iglesiente-Guspinese; Edizioni Nuova Prhomos: Città di Castellu, Italy, 2013.

40. Istituto Superiore per la protezione e la ricerca ambientale-ISPRA. Linee Guida per la Tutela, Gestione e Valorizzazione di siti e Parchi Geo-Minerari. Proposte e Prospettive per la Crescita e la Sostenibilità del Settore (Manuals and Guidelines); ISPRA, Dipartimento Difesa della Natura Servizio Aree Protette e Pianificazione Territoriale: Rome, Italy, 2008.

41. Hose, T. Geotourism and interpretation. In Geotourism. Sustainability, Impacts and Management, 1st ed.; Dowling, R., Newsome, D., Eds.; Elsevier Butterworth-Heinemann: Burlington, MA, USA, 2006; pp. 221-241.

(C) 2019 by the authors. Licensee MDPI, Basel, Switzerland. This article is an open access article distributed under the terms and conditions of the Creative Commons Attribution (CC BY) license (http://creativecommons.org/licenses/by/4.0/). 